Published in final edited form as:

Intensive Care Med. 2015 March ; 41(3): 470-478. doi:10.1007/s00134-015-3648-x.

\title{
Plasma soluble thrombomodulin levels are associated with mortality in the acute respiratory distress syndrome
}

\author{
Anil Sapru, \\ Department of Pediatrics, University of California, San Francisco, CA, USA \\ Department of Pediatrics, Box 0106, Room M680B, 505 Parnassus, San Francisco, CA \\ 94143-0106, USA \\ Carolyn S. Calfee, \\ Medicine and Anesthesia, University of California, San Francisco, CA, USA \\ Kathleen D. Liu, \\ Medicine and Anesthesia, University of California, San Francisco, CA, USA \\ Kirsten Kangelaris, \\ Medicine and Anesthesia, University of California, San Francisco, CA, USA \\ Helen Hansen, \\ Molecular Epidemiology Laboratory, University of California, San Francisco, CA, USA \\ Ludmila Pawlikowska, \\ Anesthesia and Perioperative Care, University of California, San Francisco, CA, USA \\ Institute for Human Genetics, University of California, San Francisco, CA, USA \\ Lorraine B. Ware, \\ Department of Medicine and Pathology, Vanderbilt University, Nashville, TN, USA \\ Department of Microbiology and Immunology, Vanderbilt University, Nashville, TN, USA \\ Mustafa F. Alkhouli, \\ Department of Pediatrics, University of California, San Francisco, CA, USA \\ Jason Abbot, \\ Cardiovascular Research Institute, Departments of Medicine and Anesthesia, University of \\ California, San Francisco, CA, USA
}

Michael A. Matthay, and

Cardiovascular Research Institute, Departments of Medicine and Anesthesia, University of California, San Francisco, CA, USA

The NHLBI ARDS Network

Anil Sapru: saprua@peds.ucsf.edu

Correspondence to: Anil Sapru, saprua@peds . ucsf . edu.

Electronic supplementary material The online version of this article (doi:10.1007/s00134-015-3648-x) contains supplementary material, which is available to authorized users.

Conflicts of interest All authors declare that they have no conflict of interest. 


\section{Abstract}

Objective-Thombomodulin (TM) is an activator of protein C and a biomarker for endothelial injury. We hypothesized that (1) elevated plasma levels would be associated with clinical outcomes and (2) polymorphisms in the TM gene would be associated with plasma levels.

Patients-We studied 449 patients enrolled in the Fluid and Catheter Treatment Trial (FACTT) for whom both plasma and DNA were available. We used logistic regression and receiver operator curves (ROC) to test for associations between soluble TM (sTM) and mortality at 60 days.

Measurements and results-Plasma sTM levels were higher in non-survivors than survivors at baseline [median 147 (IQR, 95-218) vs. 89 (56-129) ng/mL, $p<0.0001$ ] and on day 3 after study enrollment [205 (146-302) vs. 127 (85-189), $p<0.0001]$. The odds of death increased by 2.4 (95\%CI 1.5-3.8, $p<0.001)$, and by $2.8(1.7-4.7, P<0.001)$ for every log increase in baseline and day 3 sTM levels, respectively, after adjustment for age, race, gender, severity of illness, fluid management strategy, baseline creatinine, and non-pulmonary sepsis as the primary cause of ARDS. By ROC analysis, plasma sTM levels discriminated between non-survivors and survivors [AUC $=72 \%(66-78 \%)$ vs. AUC $=54 \%$ for severity based on Berlin criteria). Addition of sTM improved discrimination based on APACHE III from 77 to $80 \%(P<0.03)$. sTM levels at baseline were not statistically different among subjects stratified by genotypes of tag SNPs in the TM gene.

Conclusions-Higher plasma sTM levels are associated with increased mortality in ARDS. The lack of association between the sTM levels and genetic variants suggests that the increased levels of sTM may reflect severity of endothelial damage rather than genetic heterogeneity. These findings underscore the importance of endothelial injury in ARDS pathogenesis and suggest that, in combination with clinical markers, sTM could contribute to risk stratification.

\section{Keywords}

ARDS; Thrombomodulin; Biomarkers; Endothelium; Mortality

\section{Introduction}

The acute respiratory distress syndrome (ARDS) is a syndrome of respiratory failure characterized by acute pulmonary edema and lung inflammation [1]. ARDS has an estimated incidence of approximately 200,000 patients per year in the United States, and estimates of mortality range from 18 to $58 \%[2,3]$. The majority of deaths among patients with ARDS are attributed to multi-organ failure, which is thought to be due to widespread endothelial injury $[1,4]$.

Thrombomodulin (TM) is a multi-domain transmembrane-bound glycoprotein. In its endothelial cell membrane-bound form, TM neutralizes the pro-coagulant actions of thrombin and accelerates activation of protein $\mathrm{C}$, thereby enhancing its anti-coagulant and anti-inflammatory properties [5]. In addition to its membrane-bound form, TM also exists in a circulating soluble form in the plasma. Among healthy individuals, circulating sTM is produced by cleavage and shedding of the membrane-bound TM. It represents a truncated form that lacks the transmembrane and cytoplasmic domains of membrane-bound TM. At 
baseline, sTM accounts for less than $20 \%$ of the variance in the total measured TM activity in plasma among healthy individuals $[6,7]$. However, among patients with inflammatory or vascular disease, inflammation and endothelial damage accelerate cleavage and shedding of membrane-bound TM and result in high levels of circulating sTM in plasma [5]. Among healthy individuals, lower levels of sTM are associated with an increased risk of brain infarction and cardiovascular events, whereas among patients with brain infarction and coronary artery disease, increased sTM is associated with more severe illness and higher mortality $[8,9]$.

Plasma levels of sTM are elevated among patients with ARDS, sepsis and disseminated intravascular coagulation (DIC). In patients with sepsis and DIC, increased plasma sTM is a marker of increased multi-organ failure and worse clinical outcomes [10].

TM is abundant in pulmonary capillaries, and lung resection results in a decrease in serum sTM levels [11]. Administration of recombinant TM has been shown to prolong the survival time and to ameliorate the development of ARDS in a mouse model of LPS-induced ARDS [12]. In previous small studies in patients with ARDS, we have reported that plasma and edema fluid levels of sTM were higher among non-survivors compared to survivors [13-16]. However, this association has not been tested in large multicenter studies of ARDS.

Furthermore, it is unknown whether differences in plasma sTM levels among patients reflect severity of illness, genetic differences, or both.

We hypothesized that (1) plasma sTM levels at the onset of ARDS would be associated with clinical outcomes in a large multi-center study of ARDS, and (2) polymorphisms in the TM genes would be associated with plasma levels of sTM.

\section{Materials and methods}

\section{Study population}

The study population included subjects enrolled in the ARDS Network Fluid and Catheter Treatment Trial (FACTT) for whom both DNA and plasma were available for analysis. FACTT was a multi-center trial that compared conservative and liberal strategies of fluid management using explicit protocols applied for 7 days in patients with ARDS [17, 18]. Participants were also randomly assigned to receive either a pulmonary-artery catheter or a central venous catheter in a two-by-two factorial design [17]. All patients were ventilated using a lung protective ventilation strategy. The primary outcome was mortality at 60 days before discharge home [17, 18].

The institutional review boards of each participating hospital reviewed and approved the primary study and collection of biological samples. Informed consent was obtained from all participants or their surrogates, including consent to use biospecimens of subjects. Baseline samples were collected before patient randomization, as were baseline clinical data. Day 3 samples were collected if patients were alive on study day 3. Plasma and DNA were made available for this study by the ARDS Network biorepository. 


\section{Outcome measures}

The primary outcome measure was mortality at 60 days. The secondary outcome measures were (1) the number of ventilator-free days [19] and (2) the number of organ failure-free days during the first 28 days of hospitalization [17]. We used the APACHE III score to adjust for baseline severity of illness.

\section{Plasma measurements}

Plasma levels of sTM were measured using two-antibody sandwich enzyme linked immunosorbent assays (ELISA) Asserchrome kits supplied by Diagnostica Stago. The measurements were carried out in duplicate and followed the manufacturer's protocol.

\section{SNP selection and genotyping}

We used re-sequencing data available from the Seattle SNPs website (accessed at http:// gvs.gs.washington.edu/GVS/). We selected tag SNPs in the genomic region including the TM gene and 2,000 bp upstream and downstream, using multiPop software [20] with minimum allele frequency set at $5 \%$ and $r^{2}$ at 0.8 . A total of 8 tag SNPs were genotyped.

SNPs were genotyped using commercially available technologies according to manufacturer's instructions: Illumina Golden Gate 384-plex, and template-directed primer extension with fluorescence-polarization detection (FP-TDI) utilizing the Perkin Elmer Acycloprime II kit [21]. Primer sequences are available upon request. Samples were arrayed on 96-well plates with negative and positive controls (duplicates) on each plate; two investigators blinded to clinical status scored the genotypes.

\section{Data analysis}

sTM levels were right-skewed, and we used the nonparametric Mann-Whitney and nonparametric trend tests to compare the untransformed levels among categorical groups and log-transformed the data for use in parametric tests. Comparisons across quartiles were made using the non-parametric trend test (Cochrane Armitage test). Receiver operating characteristic (ROC) curve analysis was carried out to assess the predictive value of sTM levels for mortality. The discrimination of the models was validated using 10 -fold crossvalidation techniques (repeated 10 times and averaged). Logistic regression and mixed effect Poisson regression models were used as appropriate to analyze the relationship of sTM levels to mortality, ventilator-free and organ failure-free days and to adjust for clinically significant covariates such as age, severity of illness at admission to ICU, baseline creatinine, presence or absence of non-pulmonary sepsis, and allocation to fluid management arm [22]. These covariates were chosen a priori for their clinical significance and face validity. Baseline creatinine was incorporated into the model because sTM is known to be excreted via kidneys. Statistical analysis was carried out using Stata 13 (Stata, College Station, TX, USA). 


\section{Results}

\section{Study population}

Baseline characteristics of the 449 patients included in this analysis were similar to the patients without DNA and plasma available who were excluded from this study (Table 1).

\section{Elevated baseline sTM levels are associated with clinical outcomes}

The mean plasma sTM level was $123 \mathrm{ng} / \mathrm{mL}$ [median $98 \mathrm{ng} / \mathrm{mL}$, interquartile range (IQR) 62-154 ng/mL] The baseline levels of sTM differed with the underlying risk factor for development of ARDS; specifically, patients with sepsis as the primary cause of ARDS had higher levels (Supplementary Fig. 1a). The baseline plasma sTM levels were higher among non-survivors (median $147 \mathrm{ng} / \mathrm{mL}$, IQR 95-218 ng/mL) compared to survivors (median 89 $\mathrm{ng} / \mathrm{mL}$, IQR $56-129 \mathrm{ng} / \mathrm{mL}, p<0.0001$ ) (Fig. 1a). On univariate logistic regression, the odds of death increased by 3.74 (95\% CI $2.53-5.52, p<0.001)$ for every log increase in plasma sTM levels. On multivariate logistic regression, this association remained significant after adjustment for age, gender, severity of illness (APACHE III score), presence or absence of non-pulmonary sepsis, and allocation to the conservative or liberal fluid management strategy (Table 2). Because the relationship between plasma biomarkers and mortality may be non-linear, we also tested the mortality rates of patients stratified by quartiles of plasma sTM levels. There was a stepwise increase in the mortality with increasing quartiles of plasma sTM levels $(p<0.001)$ (Fig. 2a).

Consistent with the mortality findings, there were fewer ventilator-free days and fewer cardiovascular, renal, central nervous system, hematological, and hepatic organ system failure-free days (Fig. 3a) with increasing quartiles of plasma sTM levels ( $p<0.001$ for all). Total fluid balance, presence of shock and vasopressor use increased with increasing quartiles of plasma sTM levels ( $p<0.001$ for all), whereas platelet counts decreased with increasing quartiles of sTM $(p<0.001)$. There was also a decrease in $\mathrm{PaO} 2 / \mathrm{FiO} 2$ ratio and increase in oxygen index with increasing quartiles of plasma sTM levels $(P<0.001)$. All these relationships were independent of age, gender, presence or absence of non-pulmonary sepsis, and allocation to the conservative or liberal fluid management strategy (data not shown).

Mortality in our patient cohort stratified by categories of severity based on Berlin criteria was 16 vs. 22 vs. $27 \%$ ( $P=0.09$ for trend) for mild, moderate and severe ARDS, respectively, whereas mortality in patients stratified by tertiles of baseline sTM levels was 10 vs. 20 vs. $42.9 \%(P<0.001)$.

\section{Elevated day 3 sTM levels are associated with clinical outcomes}

On day 3, the mean plasma sTM level was $181 \mathrm{ng} / \mathrm{mL}$ (median $141 \mathrm{ng} / \mathrm{mL}$, IQR 92-219 $\mathrm{ng} / \mathrm{mL}$ ) and the difference noted in baseline levels of sTM with the underlying risk factor for development of ARDS persisted on day 3 (Supplementary Fig. 1b). Day 3 plasma sTM levels were higher among non-survivors (median $205 \mathrm{ng} / \mathrm{mL}$, IQR 146-302 ng/mL) compared to survivors (median $127 \mathrm{ng} / \mathrm{mL}$, IQR 85-189 ng/mL, $p<0.0001$ ) (Fig. 1b). On univariate logistic regression, the odds of death increased by 3.82 (95\%CI $2.53-5.78, p<$ 
0.001) for every log increase in plasma sTM levels and this relationship remained significant after adjustment for age, gender, severity of illness (APACHE III score), presence or absence of non-pulmonary sepsis, and allocation to the conservative or liberal fluid management strategy (Table 2b). Similar to the analysis using baseline levels reported in the previous paragraph, there was a stepwise increase in the mortality and a decrease in the number of ventilator-free and organ failure-free days among patients stratified by quartiles of day 3 plasma sTM levels (Figs. 2b, 3b).

\section{Baseline and day 3 plasma sTM levels discriminate survivors from non-survivors at 60 days}

On analysis of receiver operating curves (ROC), both baseline and day 3 plasma sTM levels as predictors had moderately good ability to discriminate survivors from non-survivors using in-hospital mortality at 60 days as the outcome. The area under the curve (AUC) was $72 \%$ for both baseline and day 3 sTM. The addition of either baseline or day 3 sTM improved the discriminatory ability of APACHEIII score to identify survivors from non-survivors with a modest but statistically significant increase in the AUC from 77 to $80 \%(p<0.03)$ (Supplementary Fig. 2).

By comparison, the AUC for the ROC curve based on the mild, moderate and severe ARDS categories as per Berlin criteria was $54 \%$ and the $\mathrm{AUC}$ for $\mathrm{PaO} 2 / \mathrm{FiO} 2$ ratio (used as a continuous variable) was $57 \%$, whereas a combination of sTM either with categories of severity as per Berlin criteria or with PF ratio yields an ROC of 72 and $73 \%$, respectively (Fig. 4).

\section{Change in STM levels from baseline to day 3 and relationship to clinical outcomes}

Overall, sTM levels increased from baseline to day 3 [median $98 \mathrm{ng} / \mathrm{mL}$ (IQR 62-53) to median $141 \mathrm{ng} / \mathrm{mL}$ (IQR 92-219), $p<0.0001]$. This increase was greater among nonsurvivors compared to survivors (average 113 vs. $48 \mathrm{ng} / \mathrm{mL} p<0.001$ ). On ROC analysis, the difference in sTM from baseline to day 3 did not perform as well as either the baseline or the day 3 levels in discriminating survivors from non-survivors.

\section{TM SNPs and plasma sTM levels}

Baseline plasma levels of sTM stratified by genotypes of the tag SNP are depicted in Table 3. sTM levels were not statistically different among individuals carrying the various genotypes of the SNPs that were genotyped (Table 3).

\section{Discussion}

This study demonstrates that increased STM in plasma collected at baseline and day 3 is a marker of adverse clinical outcomes among patients with ARDS. Specifically, elevated plasma sTM levels provide moderate discrimination between ARDS survivors and nonsurvivors, and higher levels of plasma sTM were associated with fewer ventilator-free and organ failure-free days. These associations were significant after adjustment for age, gender, and severity of illness. There was no relationship between sTM levels in plasma and the 
genotypes of tag SNPs representing common genetic variation (minor allele frequency $>5$ $\%)$ in the TM gene.

The results from our study demonstrate the prognostic value of plasma levels of sTM measured early in the course of ARDS. However, at this time, we are not suggesting the use of thrombomodulin as a sole marker for bedside mortality prediction or decisions regarding futility, but merely emphasizing its association with mortality and the associated implications for pathogenesis and potential contribution to risk stratification in combination with other biomarkers and clinical markers.

There is increasing recognition of the clinical and biological heterogeneity within ARDS, and a combination of biomarkers and clinical predictors is superior to either of these alone for predicting mortality [23] and in predicting differential response to treatment [24]. In addition, these data also enhance our understanding of dysregulated coagulation and endothelial dysfunction as a pathogenic mechanism in ARDS and highlight the role of generalized endothelial dysfunction in ARDS contributing to adverse clinical outcomes, including multi-organ dysfunction and mortality.

In a meta-analysis of studies examining association of plasma biomarkers with mortality in ARDS, Terpstra et al. [25] reported that vWF is associated with mortality with an OR of 1.98 (1.46-2.68) per log increase in plasma vWF levels. Calfee et al. [26] reported that mortality in non-infection-related ARDS was associated with an odds ratio, 2.43 (1.57-3.75) per log increase in baseline angiopoietin-2 levels. In comparison, the odds of death increased by $2.4(95 \%$ CI $1.5-3.8, p<0.001)$ and by $2.8(1.7-4.7, P<0.001)$ for every log increase in baseline and day 3 sTM levels, respectively, in our study. We also found that plasma levels of sTM collected at baseline and day 3 have relatively good discriminatory power to differentiate survivors from non-survivors. The AUC of $72 \%$ for sTM as a single biomarker for predicting mortality compares favorably to the combined AUC of $75 \%$ for the eight best-performing biomarkers in ARDS [23]. The addition of sTM levels to APACHE III resulted in a modest but statistically significant improvement in the ability to identify patients at higher risk of death on ROC analysis (Supplementary Fig. 1).

Endothelial cell injury leads to enhanced cellular adhesion to the vessel wall, amplifying the inflammatory response and coagulation via ADAMTS13-mediated Von Willebrand factor cleavage, NETS and microparticles leading to the formation of microvascular thrombosis $[27,28]$. sTM is released from endothelial cells by proteolytic activity on the surface of endothelium by neutrophil elastase, endotoxin and TNF-a resulting in an increase in plasma sTM levels due to an increase in smaller fragments of degraded forms [29]. Endothelial cell membrane-bound TM has anti-thrombotic and anti-inflammatory properties, and excessive shedding of membrane-bound TM may lead to loss of functionally active TM, resulting in a pro-coagulant and pro-inflammatory state in patients with ARDS which may be harmful because it can activate neutrophils and fibroblasts, compromise endothelial integrity, contribute to a loss of surfactant activity, and decrease alveolar fluid clearance [30, 31]. Higher plasma STM among patients with vascular damage and endothelial dysfunction have been reported previously. In children with meningococcemia, blood vessels injured by 
vasculitis have decreased endothelial-bound TM accompanied by decreased biological availability and increased plasma levels of sTM [32].

The association of higher plasma sTM levels with adverse clinical outcomes mortality, ventilator-free and organ failure-free days in patients with ARDS reported in the present study is likely a reflection of more severe endothelial dysfunction and vascular damage to the pulmonary capillary bed, as well as probable systemic endothelial dysfunction. This is additionally supported by the association of increasing sTM levels with decreasing $\mathrm{PaO}_{2} / \mathrm{FiO}_{2}$ ratio and increasing oxygenation index (reflecting pulmonary endothelial dysfunction), increasing fluid balance and vasopressor use along with decreasing platelet counts (reflecting systemic endothelial dysfunction).

We found that baseline plasma levels of sTM were not statistically different among individuals carrying the various genotypes of the SNPs genotyped. This lack of association between the sTM levels and genotypes of the tag SNPs representing common genetic variation in the TM gene supports the conclusion that the increased levels of STM in these patients are likely a reflection of excessive shedding from the endothelial surface and reflective of the severity of endothelial damage rather than differences in the structure or biology of TM due to genetic heterogeneity among these patients.

The strengths of this study include, first, the well-characterized clinical phenotype and the multi-center cohort of patients. Second, this study presents an analysis of TM genetic polymorphisms and protein levels in the same group of patients. We studied TM among patients with ARDS at both the protein biomarker and genetic levels in order to better understand the role of TM in ARDS. Third, we chose a hypothesis-free approach within the TM gene, i.e. we did not pre-specify the SNPs to be tested within the gene but instead genotyped tag SNPs providing a comprehensive coverage of the entire gene [33]. However, like all association studies, these findings require to be replicated in a validation cohort. The primary limitation of our study is that the cohort of patients in the study were from a clinical trial and not from a broad-based group of ARDS patients.

In summary, the results from this study indicate that elevated levels of plasma sTM are associated with increased mortality and that STM levels in combination with clinical scores and other biomarkers might be useful for risk stratification in clinical trials of patients with ARDS. Higher plasma levels of sTM among ARDS patients with adverse clinical outcomes likely reflect increased inflammation and both pulmonary and systemic endothelial damage. The lack of any association between the sTM levels and genetic variants suggests that the increased levels of sTM may reflect severity of endothelial damage rather than genetic heterogeneity.

\section{Supplementary Material}

Refer to Web version on PubMed Central for supplementary material. 


\section{Acknowledgments}

The study was supported by the following research grants: NIH/NHLBI contracts N01-HR-46046-64 and N01HR-16146-54 (ARDS Network). NHLBI K23 HL085526 (AS). NHLBI HL51856 (MAM). NHLBI HL110969 (CSC) HL103836 (LBW) and an American Heart Association Established Investigator Award (LBW). National Institutes of Health, National Heart, Lung, and Blood Institute Ards Network. The following persons and institutions participated in the FACTT trial: Steering Committee Chair-G. R. Bernard; Clinical Coordinating Center-D. A. Schoenfeld, B. T. Thompson, N. Ringwood, C. Oldmixon, F. Molay, A. Korpak, R. Morse, D. Hayden, M. Ancukiewicz, A. Minihan; Protocol-Review Committee-J. G. N. Garcia, R. Balk, S. Emerson, M. Shasby, W. Sibbald; Data Safety and Monitoring Board-R. Spragg, G. Corbie-Smith, J. Kelley, K. Leeper, A. S. Slutsky, B. Turnbull, C. Vreim; National Heart, Lung, and Blood Institute-A. L. Harabin, D. Gail, P. Lew, M. Waclawiw; ARDS Clinical Trials Network Consultant-P. Parsons; Clinical Centers-University of Washington, Harborview-L. Hudson, K. Steinberg, M. Neff, R. Maier, K. Sims, C. Cooper, T. Berry-Bell, G. Carter, L. Andersson; University of Michigan-G. B. Toews, R. H. Bartlett, C. Watts, R. Hyzy, D. Arnoldi, R. Dechert, M. Purple; University of Maryland-H. Silverman, C. Shanholtz, A. Moore, L. Heinrich, W. Corral; Johns Hopkins University—R. Brower, D. Thompson, H. Fessler, S. Murray, A. Sculley; Cleveland Clinic Foundation-H. P. Wiedemann, A. C. Arroliga, J. Komara, T. Isabella, M. Ferrari; University Hospitals of Cleveland-J. Kern, R. Hejal, D. Haney; MetroHealth Medical Center-A. F. Connors; University of Colorado Health Sciences Center-E. Abraham, R. McIntyre, F. Piedalue; Denver Veterans Affairs Medical Center-C. Welsh; Denver Health Medical Center-I. Douglas, R. Wolkin; St. Anthony Hospital—T. Bost, B. Sagel, A. Hawkes; Duke University—N. MacIntyre, J. Govert, W. Fulkerson, L. Mallatrat, L. Brown, S. Everett, E. VanDyne, N. Knudsen, M. Gentile; University of North Carolina-P. Rock, S. Carson, C. Schuler, L. Baker, V. Salo; Vanderbilt University-A. P. Wheeler, G. Bernard, T. Rice, B. Christman, S. Bozeman, T. Welch; University of Pennsylvania-P. Lanken, J. Christie, B. Fuchs, B. Finkel, S. Kaplan, V. Gracias, C. W. Hanson, P. Reilly, M. B. Shapiro, R. Burke, E. O’Connor, D. Wolfe; Jefferson Medical College-J. Gottlieb, P. Park, D. M. Dillon, A. Girod, J. Furlong; LDS Hospital-A. Morris, C. Grissom, L. Weaver, J. Orme, T. Clemmer, R. Davis, J. Gleed, S. Pies, T. Graydon, S. Anderson, K. Bennion, P. Skinner; McKay-Dee Hospital—C. Lawton, J. d'Hulst, D. Hanselman; Utah Valley Regional Medical Center-K. Sundar, T. Hill, K. Ludwig, D. Nielson; University of California, San Francisco-M. A. Matthay, M. Eisner, B. Daniel, O. Garcia; San Francisco General-J. Luce, R. Kallet; University of California, San Francisco, Fresno-M. Peterson, J. Lanford; Baylor College of Medicine-K. Guntupalli, V. Bandi, C. Pope; Baystate Medical Center-J. Steingrub, M. Tidswell, L. Kozikowski; Louisiana State University Health Sciences Center-B. deBoisblanc, J. Hunt, C. Glynn, P. Lauto, G. Meyaski, C. Romaine; Louisiana State University Earl K. Long Center-S. Brierre, C. LeBlanc, K. Reed; Alton-Ochsner Clinic Foundation-D. Taylor, C. Thompson; Tulane University Medical Center-F. Simeone, M. Johnston, M. Wright; University of Chicago-G. Schmidt, J. Hall, S. Hemmann, B. Gehlbach, Vinayak, W. Schweickert; Northwestern University—J. Dematte D’Amico, H. Donnelly; University of Texas Health Sciences Center-A. Anzueto, J. McCarthy, S. Kucera, J. Peters, T. Houlihan, R. Steward, D. Vines; University of Virginia_J. Truwit, A. F. Connors, M. Marshall, W. Matsumura, R. Brett; University of Pittsburgh-M. Donahoe, P. Linden, J. Puyana, L. Lucht, A. Verno; Wake Forest UniversityR. D. Hite, P. Morris, A. Howard, A. Nesser, S. Perez; Moses Cone Memorial Hospital-P. Wright, C. Carter-Cole, J. McLean; St. Paul's Hospital, Vancouver-J. Russell, L. Lazowski, K. Foley; Vancouver General Hospital-D. Chittock, L. Grandolfo; Mayo Foundation-M. Murray.

\section{References}

1. Ware LB, Matthay MA. The acute respiratory distress syndrome. N Engl J Med. 2000; 342:13341349. [PubMed: 10793167]

2. Rubenfeld GD, Caldwell E, Peabody E, Weaver J, Martin DP, Neff M, Stern EJ, Hudson LD. Incidence and outcomes of acute lung injury. N Engl J Med. 2005; 353:1685-1693. [PubMed: 16236739]

3. Zimmerman JJ, Akhtar SR, Caldwell E, Rubenfeld GD. Incidence and outcomes of pediatric acute lung injury. Pediatrics. 2009; 124:87-95. [PubMed: 19564287]

4. Khadaroo RG, Marshall JC. ARDS and the multiple organ dysfunction syndrome. Common mechanisms of a common systemic process. Crit Care Clin. 2002; 18:127-141. [PubMed: 11910726]

5. Boffa MC, Karmochkine M. Thrombomodulin: an overview and potential implications in vascular disorders. Lupus. 1998; 7(Suppl 2):S120-S125. [PubMed: 9814688]

6. Maruyama I, Shinmyozu K. Soluble thrombomodulin: as a marker of endothelial injury. Rinsho Byori. 1994; 42:563-568. [PubMed: 8051797]

7. Ohlin AK, Larsson K, Hansson M. Soluble thrombomodulin activity and soluble thrombomodulin antigen in plasma. J Thromb Haemost. 2005; 3:976-982. [PubMed: 15869594] 
8. Constans J, Conri C. Circulating markers of endothelial function in cardiovascular disease. Clin Chim Acta. 2006; 368:33-47. [PubMed: 16530177]

9. Olivot JM, Labreuche J, Aiach M, Amarenco P. Soluble thrombomodulin and brain infarction: casecontrol and prospective study. Stroke. 2004; 35:1946-1951. [PubMed: 15192246]

10. Lin SM, Wang YM, Lin HC, Lee KY, Huang CD, Liu CY, Wang CH, Kuo HP. Serum thrombomodulin level relates to the clinical course of disseminated intravascular coagulation, multiorgan dysfunction syndrome, and mortality in patients with sepsis. Crit Care Med. 2008; 36:683-689. [PubMed: 18431261]

11. Maeda S, Takahashi S, Sato M. Serum thrombomodulin as a newly identified biomarker for postoperative lung injury: a prospective observational study. Tohoku J Exp Med. 2012; 228:135141. [PubMed: 22990590]

12. Kudo D, Toyama M, Aoyagi T, Akahori Y, Yamamoto H, Ishii K, Kanno E, Maruyama R, Kaku M, Kushimoto S, Kawakami K. Involvement of high mobility group box 1 and the therapeutic effect of recombinant thrombomodulin in a mouse model of severe acute respiratory distress syndrome. Clin Exp Immunol. 2013; 173:276-287. [PubMed: 23607598]

13. Agrawal A, Zhuo H, Brady S, Levitt J, Steingrub J, Siegel MD, Soto G, Peterson MW, Chesnutt MS, Matthay MA, Liu KD. Pathogenetic and predictive value of biomarkers in patients with ALI and lower severity of illness: results from two clinical trials. Am J Physiol Lung Cell Mol Physiol. 2012; 303:L634-L639. [PubMed: 22865551]

14. Matthay MA, Ware LB. Plasma protein C levels in patients with acute lung injury: prognostic significance. Crit Care Med. 2004; 32:S229-S232. [PubMed: 15118523]

15. McClintock D, Zhuo H, Wickersham N, Matthay MA, Ware LB. Biomarkers of inflammation, coagulation and fibrinolysis predict mortality in acute lung injury. Crit Care. 2008; 12:R41. [PubMed: 18358078]

16. Ware LB, Fang X, Matthay MA. Protein C and thrombomodulin in human acute lung injury. Am J Physiol Lung Cell Mol Physiol. 2003; 285:L514-L521. [PubMed: 12754194]

17. Wheeler AP, Bernard GR, Thompson BT, Schoenfeld D, Wiedemann HP, deBoisblanc B, Connors AF Jr, Hite RD, Harabin AL. Pulmonary-artery versus central venous catheter to guide treatment of acute lung injury. N Engl J Med. 2006; 354:2213-2224. [PubMed: 16714768]

18. Wiedemann HP, Wheeler AP, Bernard GR, Thompson BT, Hayden D, deBoisblanc B, Connors AF $\mathrm{Jr}$, Hite RD, Harabin AL. Comparison of two fluid-management strategies in acute lung injury. N Engl J Med. 2006; 354:2564-2575. [PubMed: 16714767]

19. Schoenfeld D. Statistical evaluation of ventillator-free days as an efficacy measure in clinical trials of treatments for acute respiratory distress syndrome. Crit Care Med. 2002; 30:1772-1777. [PubMed: 12163791]

20. Carlson CS, Eberle MA, Rieder MJ, Yi Q, Kruglyak L, Nickerson DA. Selecting a maximally informative set of single-nucleotide polymorphisms for association analyses using linkage disequilibrium. Am J Hum Genet. 2004; 74:106-120. [PubMed: 14681826]

21. Hsu TM, Kwok PY. Homogeneous primer extension assay with fluorescence polarization detection. Methods Mol Biol. 2003; 212:177-187. [PubMed: 12491910]

22. Vittinghoff, E. Regression methods in biostatistics : linear, logistic, survival, and repeated measures models. New York: Springer; 2005.

23. Ware LB, Koyama T, Billheimer DD, Wu W, Bernard GR, Thompson BT, Brower RG, Standiford TJ, Martin TR, Matthay MA. Prognostic and pathogenetic value of combining clinical and biochemical indices in patients with acute lung injury. Chest. 2010; 137:288-296. [PubMed: 19858233]

24. Calfee CS, Delucchi K, Parsons PE, Thompson BT, Ware LB, Matthay MA. Subphenotypes in acute respiratory distress syndrome: latent class analysis of data from two randomised controlled trials. Lancet Respir Med. 2014; 2:611-620. [PubMed: 24853585]

25. Terpstra ML, Aman J, van Nieuw Amerongen GP, Groeneveld AB. Plasma biomarkers for acute respiratory distress syndrome: a systematic review and meta-analysis. Crit Care Med. 2014; 42:691-700. [PubMed: 24158164] 
26. Calfee CS, Gallagher D, Abbott J, Thompson BT, Matthay MA. Plasma angiopoietin-2 in clinical acute lung injury: prognostic and pathogenetic significance. Crit Care Med. 2012; 40:1731-1737. [PubMed: 22610178]

27. Delabranche X, Boisrame-Helms J, Asfar P, Berger A, Mootien Y, Lavigne T, Grunebaum L, Lanza F, Gachet C, Freyssinet JM, Toti F, Meziani F. Microparticles are new biomarkers of septic shock-induced disseminated intravascular coagulopathy. Intensive Care Med. 2013; 39:16951703. [PubMed: 23793890]

28. Levi M, van der Poll T. Endothelial injury in sepsis. Intensive Care Med. 2013; 39:1839-1842. [PubMed: 23925547]

29. Takano S, Kimura S, Ohdama S, Aoki N. Plasma thrombomodulin in health and diseases. Blood. 1990; 76:2024-2029. [PubMed: 2173634]

30. Vadasz I, Morty RE, Olschewski A, Konigshoff M, Kohstall MG, Ghofrani HA, Grimminger F, Seeger W. Thrombin impairs alveolar fluid clearance by promoting endocytosis of $\mathrm{Na}+\mathrm{K}+-$ ATPase. Am J Respir Cell Mol Biol. 2005; 33:343-354. [PubMed: 16014898]

31. Gunther A, Mosavi P, Heinemann S, Ruppert C, Muth H, Markart P, Grimminger F, Walmrath D, Temmesfeld-Wollbruck B, Seeger W. Alveolar fibrin formation caused by enhanced procoagulant and depressed fibrinolytic capacities in severe pneumonia. Comparison with the acute respiratory distress syndrome. Am J Respir Crit Care Med. 2000; 161:454-462. [PubMed: 10673185]

32. Faust SN, Levin M, Harrison OB, Goldin RD, Lockhart MS, Kondaveeti S, Laszik Z, Esmon CT, Heyderman RS. Dysfunction of endothelial protein C activation in severe meningococcal sepsis. N Engl J Med. 2001; 345:408-416. [PubMed: 11496851]

33. Wacholder S, Chanock S, Garcia-Closas M, El Ghormli L, Rothman N. Assessing the probability that a positive report is false: an approach for molecular epidemiology studies. J Natl Cancer Inst. 2004; 96:434-442. [PubMed: 15026468] 
Take-home message

Increased plasma levels of soluble thrombomodulin at day 1 and day 3 after the onset of ARDS are associated with increased mortality and organ failure. 

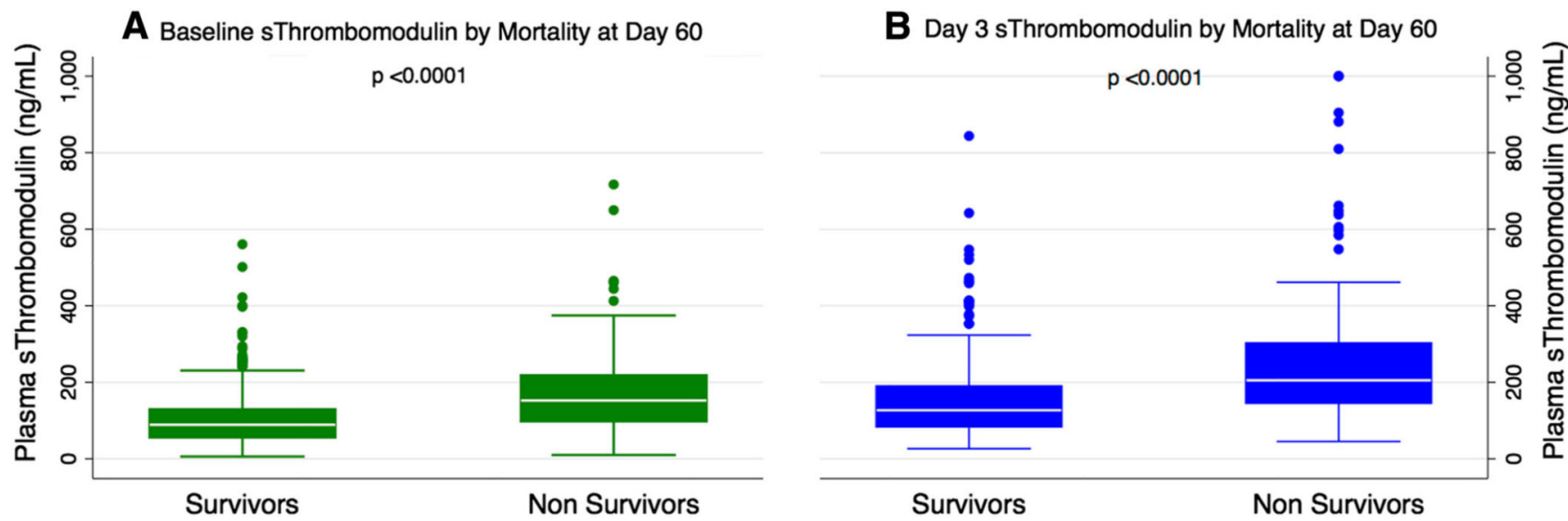

Fig. 1.

sTM levels collected at a baseline and $\mathbf{b}$ day 3 among subjects with ARDS stratified by mortality. sTM levels were higher among non-survivors $(p<0.0001)$ 

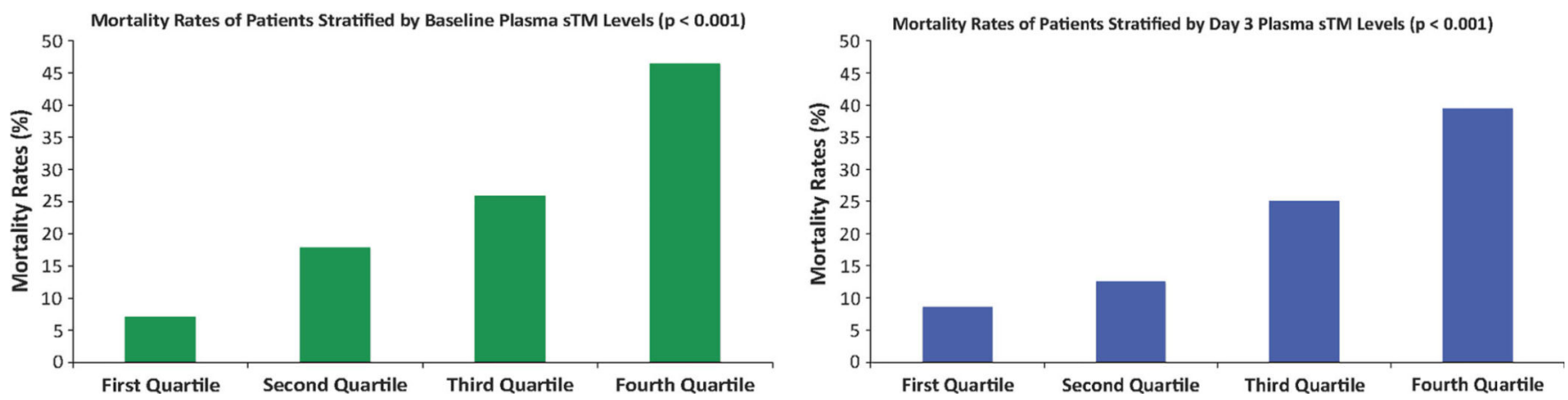

Fig. 2.

Mortality at 60 days ( $y$-axis) among subjects with ARDS stratified by quartiles of plasma sTM levels ( $x$-axis) at baseline (a) and day 3 (b). There is increasing mortality with increasing quartiles of plasma sTM levels $(p<0.001)$ 
Organ Failure-Free Days Stratified by Baseline sTM

m First Quartile $\quad$ Second Quartile $\quad$ Third Quartile

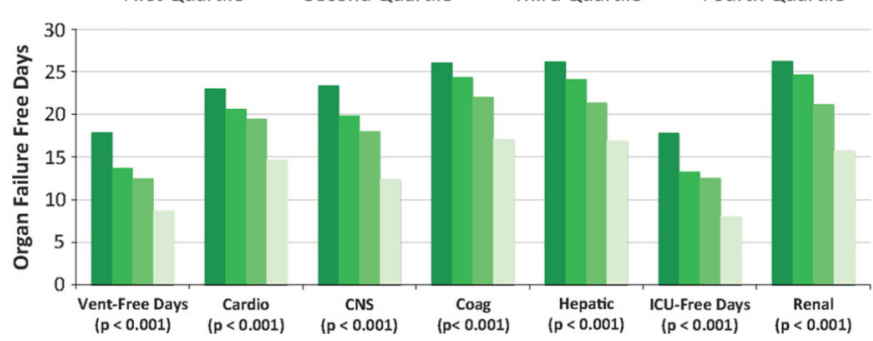

Organ Failure-Free Days Stratified by Day 3 STM

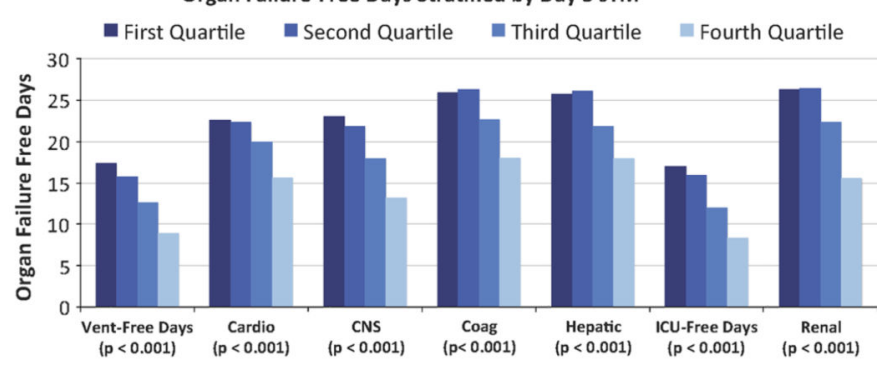

Fig. 3.

Ventilator-free days and organ failure-free days ( $y$-axis) among subjects with ARDS stratified by quartiles of plasma sTM levels ( $x$-axis) at baseline (a) and Day $3(\mathbf{b})$. There are fewer ventilator-free and organ failure-free days with increasing quartiles of plasma sTM levels $(P<0.001)$ 

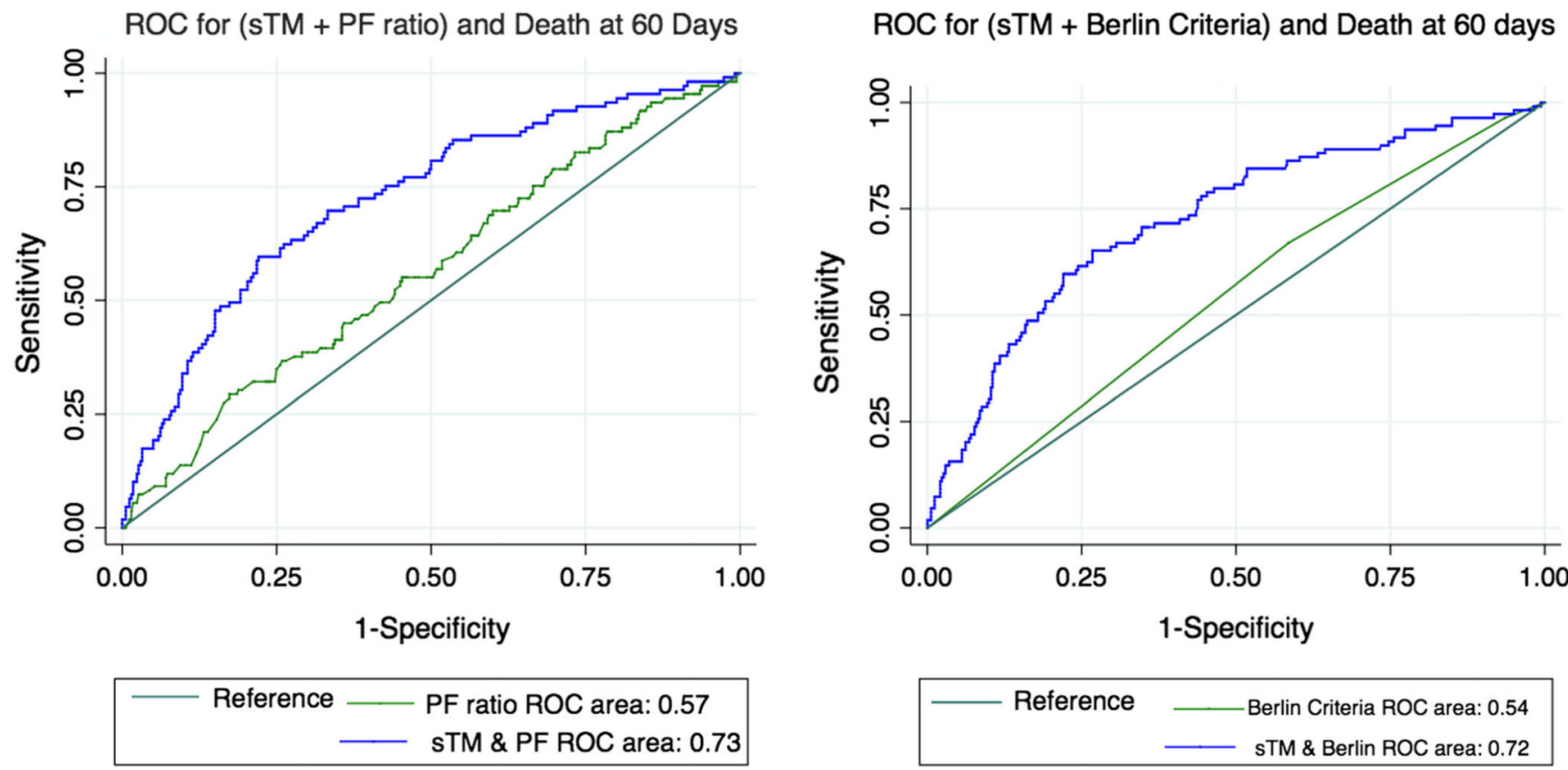

Fig. 4.

Receiver operator characteristic curves depicting improvement in the discriminatory ability of categories of severity based on Berlin criteria (right panel) and PF ratio (left panel) with addition of sTM levels to the model. The area under curve increased from 54 to $72 \%$ ( $p<$ $0.001)$ and 57 to $73 \%(p<0.001)$, respectively 


\section{Table 1}

Baseline characteristics of the study cohort

\begin{tabular}{|c|c|c|c|}
\hline Variable & $\begin{array}{l}\text { Patients with plasma } \\
\text { and DNA }(n=449)\end{array}$ & $\begin{array}{l}\text { Patients without plasma } \\
\text { and DNA }(n=545)\end{array}$ & $P$ \\
\hline Age in years $($ mean $\pm S D)$ & $49.8 \pm 15.6$ & $49.7 \pm 16.4$ & 0.9 \\
\hline Male $(\%)$ & 54 & 53 & 0.7 \\
\hline Ethnicity & & & $<0.005$ \\
\hline Caucasian $(\%)$ & 69 & 59 & \\
\hline African-American (\%) & 19 & 24 & \\
\hline Hispanic (\%) & 12 & 16 & \\
\hline \multicolumn{2}{|l|}{ Clinical disorders associated with ARDS } & & 0.66 \\
\hline Pneumonia $(\%)$ & 45 & 49 & \\
\hline Sepsis $(\%)$ & 22 & 24 & \\
\hline Multiple transfusions (\%) & 1 & 1 & \\
\hline Trauma $(\%)$ & 9 & 6 & \\
\hline Aspiration (\%) & 16 & 14 & \\
\hline Other $(\%)$ & 7 & 6 & \\
\hline Use of vasopressors (\%) & 34 & 33 & 0.72 \\
\hline APACHE III score & 95 & 94 & 0.7 \\
\hline Fluid management (conservative \%) & 48 & 52 & 0.24 \\
\hline Mortality at 60 days (\%) & 24.3 & 28.8 & 0.11 \\
\hline Ventilator-free days median (IQR) & $17(0-23)$ & $18(0-23)$ & 0.27 \\
\hline
\end{tabular}



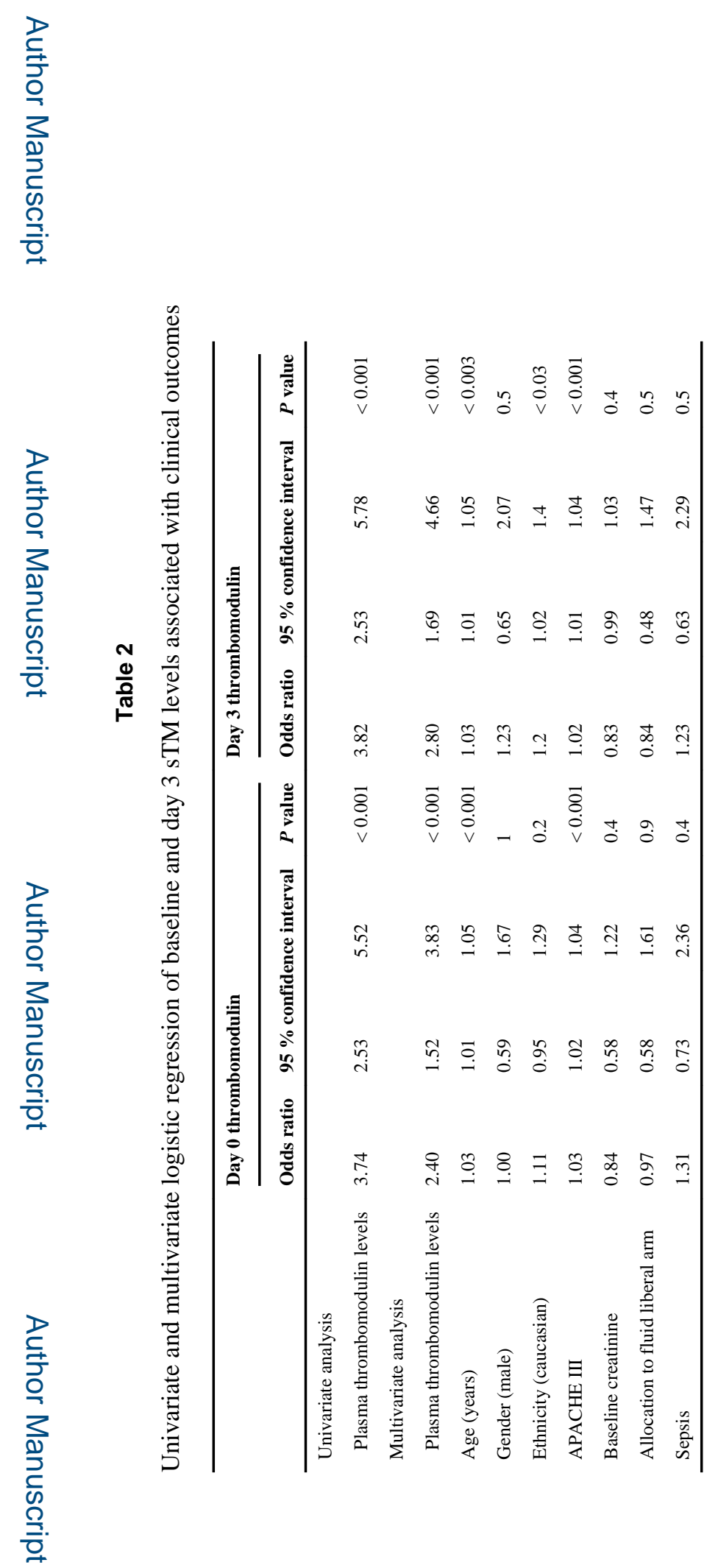

Intensive Care Med. Author manuscript; available in PMC 2016 March 01. 
Table 3

Baseline sTM levels stratified by genotypes of tag-SNPs in the thrombomodulin gene

\begin{tabular}{|c|c|c|c|}
\hline SNP & $n$ & Median (IQR) & $P$ value \\
\hline \multicolumn{4}{|l|}{ rs 1042580} \\
\hline Minor homozygote (GG) & 64 & $112.8(83-188.3)$ & 0.7 \\
\hline Heterozygote (AG) & 205 & $90.5(58-147.4)$ & \\
\hline Major homozygote (AA) & 178 & $100.1(69.6-148.1)$ & \\
\hline \multicolumn{4}{|l|}{ rs1962 } \\
\hline Minor homozygote (GG) & 32 & $111.9(72.1-179.8)$ & 0.2 \\
\hline Heterozygote (AG) & 148 & $97.6(67.4-150.3)$ & \\
\hline Major homozygote (AA) & 268 & $98.4(59.6-158.4)$ & \\
\hline \multicolumn{4}{|l|}{ rs 2007363} \\
\hline Minor homozygote (AA) & 26 & $118(69.3-164.7)$ & 0.4 \\
\hline Heterozygote (AC) & 143 & $99(66-149)$ & \\
\hline Major homozygote (CC) & 279 & $97.6(60-160)$ & \\
\hline \multicolumn{4}{|l|}{ rs3176118 } \\
\hline Minor homozygote (OO) & 4 & $90.5(43.2-192.8)$ & 0.08 \\
\hline Heterozygote (XO) & 75 & $88.8(56.8-129.2)$ & \\
\hline Major homozygote (XX) & 368 & $100.5(65.4-163.1)$ & \\
\hline \multicolumn{4}{|l|}{ rs3176123 } \\
\hline Minor homozygote (CC) & 16 & $95.9(49.8-144.7)$ & 0.06 \\
\hline Heterozygote (AC) & 107 & $87.7(59.1-128.3)$ & \\
\hline Major homozygote (AA) & 324 & $98.4(59.6-158.4)$ & \\
\hline \multicolumn{4}{|l|}{ rs 3176130} \\
\hline Minor homozygote (AA) & 0 & & 0.5 \\
\hline Heterozygote (AG) & 12 & $116.3(67.2-187.8)$ & \\
\hline Major homozygote (GG) & 437 & $97.8(62.4-153.4)$ & \\
\hline \multicolumn{4}{|l|}{ rs 3176133} \\
\hline Minor homozygote (CC) & 3 & $74.9(38.2-331.5)$ & 0.50 \\
\hline Heterozygote (AC) & 12 & $127.9(84.2-176.8)$ & \\
\hline Major homozygote (AA) & 433 & $98.1(62.2-153.4)$ & \\
\hline \multicolumn{4}{|l|}{ rs3176134 } \\
\hline Minor homozygote (AA) & 0 & & 0.8 \\
\hline Heterozygote (AG) & 5 & $118.9(73-129.2)$ & \\
\hline Major homozygote (GG) & 444 & $98(62.2-155.4)$ & \\
\hline
\end{tabular}

Intensive Care Med. Author manuscript; available in PMC 2016 March 01. 